\title{
Cytogenetic analyses of culture failures by comparative genomic hybridisation (CGH) - Re-evaluation of chromosome aberration rates in early spontaneous abortions
}

\author{
Barbara Fritz ${ }^{*, 1,4}$, Christian Hallermann ${ }^{2,4}$, Jürgen Olert ${ }^{2}$, Brigitte Fuchs ${ }^{1,2}$, Marion Bruns ${ }^{1}$, \\ Mücevher Aslan ${ }^{1}$, Stefan Schmidt ${ }^{3}$, Wiltrud Coerdt ${ }^{2}$, Horst Müntefering $^{2}$ and Helga Rehder $^{1}$
}

${ }^{1}$ Institut für Klinische Genetik, Philipps-Universität Marburg, Germany; ${ }^{2}$ Abteilung für Kinderpathologie am Institut für Pathologie, Gutenberg-Universität Mainz, Germany; ${ }^{3}$ Klinik für Geburtshilfe, Philipps-Universität Marburg, Germany

Comparative genomic hybridisation $(\mathrm{CGH})$ represents an alternative molecular-cytogenetic technique capable of detecting chromosomal imbalances by reverse fluorescence in situ hybridisation. As the technique uses genomic DNA for assessment it does not rely on metaphase chromosomes in the test material and thus circumvents technical problems associated with tissue culturing. In the present study, we applied CGH to identify chromosome anomalies in 60 spontaneous abortions of the first trimester, that had failed to grow in culture. In 57 out of 60 cases CGH analyses were successful. The overall aneuploidy rate detected was $72 \%$. Trisomy was the predominant chromosome anomaly accounting for $68.0 \%$ of abnormal abortions, followed by triploidy $(17.1 \%)$ and monosomy $X(9.8 \%)$. An unbalanced structural rearrangement was found in one (2.4\%) abortion. Most frequently involved in trisomies were chromosomes $16(32.1 \%), 7$ and $22(10.7 \%$ each), 4, 13, 15, and 21 ( $7.2 \%$ each). Three triploid cases and one complete mole were detected by microsatellite analysis as supplementary method. CGH data on culture failures were compared with data derived from 4693 successfully karyotyped first trimester spontaneous abortions, resulting in a chromosome aberration rate of $64.8 \%$. The distribution of the different chromosome anomalies was similar with the exception of a higher rate of trisomies 7 and of XYY-triploidies in the culture failures. Based on our data we suggest that the genetic contribution to pregnancy loss is still underestimated. Investigating abortion tissues hitherto unassessed by conventional methods, we suggest that the contribution of chromosome aberrations to first trimester pregnancy loss is nearly 70\%. European Journal of Human Genetics (2001) 9, 539-547.

Keywords: Comparative genomic hybridisation $(\mathrm{CGH})$; spontaneous abortions; culture failures; chromosome aberration rate

Introduction

Comparative genomic hybridisation (CGH) facilitates detection of DNA sequence gains and sequence losses throughout

*Correspondence: B Fritz, Correspondence: B Fritz, Institut für Klinische Genetik, Philipps-Universität, Bahnhofstrasse 7, D-35033 Marburg, Tel: +496421 2866703; Fax: +496421 2863984;

E-mail: fritzb@mailer.uni-marburg.de

${ }^{4}$ Barbara Fritz and Christian Hallermann contributed equally to this work Received 1 February 2001; revised 17 April 2001; accepted 26 April 2001 the genome in a singular double-colour FISH. It was first established to cytogenetically investigate tissues with multiple chromosomal rearrangements, ie tumour tissues. ${ }^{1}$ More recently, the use of the technique has been extended to characterization of whole or partial aneuploidies in fetuses or neonatales. $^{2-5}$ The technique has also proved useful for retrospective identification of familial, even cryptic translocations, or identification of hitherto unclassifiable de novo chromosomal rearrangements. ${ }^{6-8} \mathrm{CGH}$ even allows investigation of archival formalin fixed and paraffin embedded 
placental or foetal tissues. ${ }^{9,10}$ Latest results show the ability of CGH to detect aneuploidies in single cells eg in association with preimplantation diagnosis. ${ }^{11} \mathrm{CGH}$ circumvents problems arising from tissue culture and allows testing in samples unanalysable by conventional cytogenetic analysis. Suspecting adverse effects of hitherto unidentified chromosome imbalances on culture growth and thus a high aberration rate in culture failures, we applied CGH to archival frozen chorionic villi of early spontaneous abortions that had failed to grow in culture.

\section{Material and methods}

Tissue samples and controls

Foetal or chorionic tissues had been collected as part of a cytogenetic study on spontaneous abortions at the Department of Paedopathology Mainz (MZ=32 cases) and the Institute of Clinical Genetics Marburg ( $M R=28$ cases). Samples were cleansed from maternal decidua, blood clots and mucus. Fifty to $200 \mathrm{mg}$ CVS per case were stored deep frozen $\left(-80^{\circ} \mathrm{C}\right)$ to facilitate later DNA extraction. The remainder samples were used for conventional cytogenetic and histological examinations. If an embryo was present, it was examined and photographed. As for the abortion cases from Marburg, parental blood had been collected in addition and stored deep frozen. In the present investigation DNA was extracted from stored frozen samples in 60 cases of first trimester spontaneous abortions that had failed to grow in culture, culture failure having impeded cytogenetic analysis. DNA was used for retrospective chromosome analyses by CGH. DNA from parental blood samples was extracted for microsatellite analysis. A total of 6631 abortion specimens (MZ/MR 6198/ 433) of gestational weeks 6 to 12 having been tested by conventional cytogenetic analysis served as controls.

For statistical analysis Fishers' exact test was used. Statistical significance was accepted at the probability level of $<0.05$.

\section{CGH analysis}

Stored CVS/foetal tissue samples were disaggregated under liquid nitrogen. Genomic DNA was isolated by the saltingout method. ${ }^{12}$ Reference DNA was extracted from peripheral blood of a karyotypically normal male. CGH metaphase preparations, DNA labelling, hybridisation and detection were performed as described previously. ${ }^{13}$ To detect ratio changes in the test DNA equal amounts (300-500 ng each) of FITC labelled sample- and rhodamine labelled controlDNA were precipitated in the presence of a $30 \mu \mathrm{g}$ Cot-1-DNA fraction (GIBCO-BRL).

Slides were analysed with a Zeiss epifluorescence microscope with selective filtres equipped with a charged-coupled device camera. Three colour images with green (FITC), red (rhodamine) and blue (DAPI for counterstaining of the chromosomes) were obtained from 10-15 metaphases in each hybridisation. The image representing DAPI was inverted and used for semiautomatic karyotyping. Green (test-DNA) and red (reference DNA) fluorescence ratios were determined for each chromosome. After background substraction, fluorescence intensities were measured along the length of each homologue chromosome. For each chromosome, fluorescent ratio profiles (FR) were calculated as quotients of green and red fluorescence intensities and normalised to 1.0 representing the balanced state of the chromosomal copy number. An upper threshold of $>1.20$ was used to define gain of chromosomal material, while a lower threshold of $<0.80$ was used to indicate loss of chromosomal material. ${ }^{14}$ For processing the captured images and for analysis function of automated generation of chromosome fluorescence intensity profiles, the ISIS digital image analysis system (MetaSystems, Altlussheim, Germany) and the Cytovision CGH program (Applied Imaging Cooperations) were used.

\section{FISH and microsatellite analysis}

All samples shown to be chromosomally balanced in CGH underwent interphase FISH or microsatellite analysis to determine ploidy. Known labelling artifacts associated with GC rich regions of $1 \mathrm{p} 32 \rightarrow$ pter, $16 \mathrm{p}, 19$, and 22 can lead to a deviation from a 1.0 FR value and thus to false positive interpretations. ${ }^{13,15}$ Whenever these chromosomes were involved, we applied supplementary methods. Interphase FISH was performed on CVS touch preparations. Chromosome specific centromeric probes were implemented according to standard protocols for their hybridisation and detection. Nuclei were counterstained with DAPI and the number of hybridisation signals per cell were counted in at least 50 nuclei. For microsatellite analysis chromosome specific polymorphic markers were used. All primers were obtained from Research Genetics Inc. (Huntsville, AL, USA) using the Map Pair set 6.0. Individual markers were chosen primarily based on their heterozygosities, most being 0.8 and higher. Details of the primers used may be obtained on request from the authors. For the studies, DNA was amplified using standard conditions and a 'high touch down protocol' with annealing temperatures of $63^{\circ} \mathrm{C}^{16}$. PCR products were separated by $8 \%$ polyacrylamide gel-electrophoresis (PAGE) and visualised by silver staining. Determinations were based on at least two informative markers. Triploidy was excluded/ confirmed by analysis of DNA polymorphisms of different autosomes.

\section{Results}

Sixty placental samples of first trimester spontaneous abortions were analysed for unbalanced chromosome aberrations by CGH (Table 1). In 57 out of 60 (95\%) cases CGH analyses were successful. In three cases (5\%) the FR-profiles were not interpretable due to poor, non-homogeneous hybridisation signals. CGH did not reveal any chromosome abnormalities in 20 of the 57 successfully analysed cases. The 
copy number representation of sex chromosomes required an appropriate choice of both reference DNA and reference metaphase spreads. Therefore, CGH analyses were performed by co-hybridisation of abortion DNA with 'male' control DNA to normal 'male' metaphase spreads. In 13 of the 20 normal cases where abortion DNA (XX) and control DNA (XY) were discordant with respect to sex, the entire $\mathrm{X}$ chromosome was over-represented in the CGH profile, and the Y chromosome showed a relative loss, consistent with $\mathrm{Y}$ material derived only from the control DNA. The remaining chromosomes showed CGH profiles with no significant deviation from a value of 1.0. Ploidy changes in the seemingly 20 normal cases were investigated by microsatellite analyses in 16 cases and by interphase FISH in four cases. Three cases (MZ-1566, MZ-2557, MR-172) which had produced a balanced $46, \mathrm{XX}$ status on CGH displayed polyploidy on microsatellite analysis with a $69, \mathrm{XXX}$ karyotype. In one case (MR-112), microsatellite analysis demonstrated paternally inherited alleles only, thus verifying a complete mole which had been suspected previously by histology. Altogether, CGH identified 37 of the 41 chromosomally aberrant cases (90\%). In four cases chromosome aberration was detected by supplementary methods.

Four of the 41 chromosomally abnormal cases revealed imbalances of the sex chromosomes. In two cases CGH analysis showed two copies of the $X$ chromosome in the test DNA and a balanced state of Yp indicating a XXY-status. In two cases gain of a $Y$ chromosome became evident indicating a XYY gonosome constellation. These cases were highly suspective of triploidy. In all cases triploidy was confirmed by the appearance of a third allele or by an increased dosage of a unique parental allele raising the total number of triploids to seven. Partial hydatidiform mole in six of the seven triploid cases suggested paternal origin of the additional haploid chromosome set. This could be confirmed by microsatellite analysis in three of the cases in which parental DNA was available.

In four of the 41 abnormal cases the average green/red FR profile indicated a single $\mathrm{X}$ chromosome and absence of a $\mathrm{Y}$ chromosome in the test genome. The $45, \mathrm{X}$ karyotype could be confirmed in two out of four cases by microsatellite analysis revealing loss of the paternal $\mathrm{X}$ chromosome. Autosomal trisomies, comprising chromosomes 2, 4, 7, 8, $10,13,15,16,18,19,21$ and 22 , were evidenced by CGH in 28 of the 41 chromosomally abnormal cases (Table 1, Figure 1). In three cases (MZ-1682, MR-162, MZ-4677) the average FR-ratio of chromosomes 2, 19, and 22, respectively, was $<1.2$ along the entire chromosome. Microsatellite analysis, however, revealed two alleles of normal and one allele of reduced intensity. Based on these data these karyotypes could be defined as mosaic karyotypes. CGH analysis detected one segmental aneusomy (MZ-1520). Weak staining of the distal region of the short arm of chromosome 5 indicated underrepresentation of this chromosomal region in the test genome. The parents were excluded as translocation carriers.
Thus, CGH allowed the identification of a de novo del(5p) defining the breakpoint at 5p14 (Figure 1). In total, aneuploidy was detected in 40 cases $(70.2 \%)$, respectively in 41 cases $(72.0 \%)$ if the abortion with paternal disomy of all chromosomes and complete hydatidiform mole of the placenta was included (Table 2). Trisomy was the predominant chromosome anomaly accounting for $68.3 \%$ of all abnormal abortions, followed by triploidy (17.1\%), and monosomy X (9.8\%). An unbalanced structural rearrangement was found in one (2.4\%) abortion. Chromosomes 16 (32.1\%), 7 and 22 (10.7\% each), 4, 13, 15, and 21 (7.2\% each) were most frequently involved in trisomies. Three mosaic karyotypes were found corresponding to $7.5 \%$ of the chromosomally abnormal specimens (Table 2).

$\mathrm{CGH}$ results of culture failures were compared to consecutive series of unselected first trimester spontaneous abortions. A total of 6198 cases were analysed in Mainz (MZ) and 433 cases in Marburg (MR). The two studies were discordant regarding the culture failure rate $(12.5 \%$ in $\mathrm{MR}$ vs $30.4 \%$ in $\mathrm{MZ}$ ) and the sex ratio. In the MR-study the male: female sex ratio of 110 spontaneous abortions with normal karyotype was 1.0. The MZ-study showed a sex ratio of 0.6 with a predominance of chromosomally normal female abortions (553:990). However, the frequency and type of chromosome anomalies detected in the two studies were similar. Pooled data are summarised in Table 3. Abnormal karyotypes were found in $64.8 \%$ of the cases and included autosomal trisomies in 53.9\%, monosomy $\mathrm{X}$ in $11.2 \%$, triploidy in $15.6 \%$, tetraploidy in $11.3 \%$, and unbalanced structural rearrangements in $9.0 \%$ of the cases. Among the triploid abortions the gonosomal constitution of XXY prevailed $(n=252)$, followed by XXX $(n=168)$ and XYY $(n=14)$.

Mean gestational week at foetal loss and maternal age did not differ between the culture failures with normal/abnormal karyotypes (9.5/10.0 weeks and 29.9/32.4 years) and the successfully karyotyped cases (9.8/9.9 weeks and 30.3/31.4 years).

\section{Discussion}

According to the literature, chromosome abnormalities account for more than $50 \%$ of early foetal losses, thus constituting the single most frequent cause of pregnancy loss in several surveys. ${ }^{17}$ Meanwhile nearly 20000 spontaneous abortions have been karyotyped and the general distribution of anomalies is well established (Figure 2). It is remarkable, however, that the highest overall abnormality rates in early spontaneous abortions were found in series with the high culture success rates. ${ }^{18-20}$ This suggests, that culture failures are most likely to be chromosomally abnormal and that the incidence of aneuploidy is still clearly underestimated since potential abnormalities in culture failures have not yet been evaluated. To fill this gap we applied the CGH technique to detect chromosome 
Table $1 \mathrm{CGH}$ results and interpretation for 57 first trimester spontaneous abortions which failed to grow in culture

\begin{tabular}{|c|c|c|c|c|c|}
\hline ID No & $\mathrm{CGH}$ & $\begin{array}{l}\text { Verification } \\
\text { of } \mathrm{CGH}\end{array}$ & $\begin{array}{l}\text { Proposed } \\
\text { karyotype } \\
\text { (origin of } \\
\text { aberration) }\end{array}$ & $\begin{array}{l}\text { Maternal } \\
\text { age }\end{array}$ & $\begin{array}{l}\text { Gestational } \\
\text { age }\end{array}$ \\
\hline MZ-383 & rev ish $X Y$ & $\mathrm{~m}$ & $46, X Y$ & 29 & $9+1$ \\
\hline MZ-2011 & rev ish $X Y$ & $\mathrm{f}$ & $46, X Y$ & 30 & 9 \\
\hline MR-40 & rev ish $X Y$ & $\mathrm{~m}$ & $46, X Y$ & 28 & 10 \\
\hline MR-198 & rev ish $X Y$ & $\mathrm{~m}$ & $46, X Y$ & 28 & 8 \\
\hline MR-259 & rev ish $X Y$ & $\mathrm{~m}$ & $46, X Y$ & 33 & 9 \\
\hline MR-531 & rev ish $X Y$ & f & $46, X Y$ & 33 & $10+2$ \\
\hline MR-599 & rev ish $X Y$ & $\mathrm{~m}$ & $46, X Y$ & 33 & 1. trim \\
\hline MZ-531 & rev ish $X X$ & $\mathrm{~m}$ & $46, x x$ & 31 & $10+4$ \\
\hline MZ-637 & rev ish $X X$ & $f$ & $46, X X$ & 29 & 7 \\
\hline MZ-1593 & rev ish $X X$ & f & $46, x X$ & 21 & $10+2$ \\
\hline MZ-2826 & rev ish $X X$ & $\mathrm{~m}$ & $46, X X$ & 33 & 8 \\
\hline MZ-4077 & rev ish $X X$ & $\mathrm{f}$ & $46, X X$ & 38 & $8-9$ \\
\hline MR-59 & rev ish $X X$ & $\mathrm{~m}$ & $46, x x$ & 28 & $7-8$ \\
\hline MR-72 & rev ish $X X$ & $\mathrm{~m}$ & $46, X X$ & 33 & 1.trim \\
\hline MR-92 & rev ish $X X$ & $\mathrm{~m}$ & $46, x \times$ & 24 & 8 \\
\hline MR-118 & rev ish XX & $\mathrm{m}$ & $46, X X$ & 28 & 11 \\
\hline \multicolumn{6}{|c|}{ Complete mole } \\
\hline MR-112 & rev ish $X X$ & $\mathrm{~m}$ & $46, X X$ & 30 & $8-9$ \\
\hline \multicolumn{6}{|l|}{ Triploidy } \\
\hline MZ-1566 & rev ish $X X$ & $\mathrm{~m} / \mathrm{f}$ & $69, x \times X$ & 37 & 9 \\
\hline MZ-2557 & rev ish $X X$ & $\mathrm{~m} / \mathrm{f}$ & $69, X X X$ & 39 & 1.trim \\
\hline MR-172 & rev ish $X X$ & $\mathrm{~m}$ & $69, \mathrm{XXX}$ (pat) & 42 & $11+4$ \\
\hline MZ-526 & rev ish $X X$ and $Y$ & $\mathrm{~m}$ & $69, X X Y$ & 34 & $12+6$ \\
\hline MZ-1438 & rev ish $X X$ and $Y$ & $m / f$ & $69, X X Y$ & 31 & 6 \\
\hline MR-81 & rev ish enh $(Y)$ & $\mathrm{m}$ & $69, \mathrm{XYY}$ (pat) & 35 & 9 \\
\hline MR-216 & rev ish enh (Y) & $\mathrm{m}$ & $69, \mathrm{XYY}$ (pat) & 24 & 9 \\
\hline \multicolumn{6}{|l|}{ Trisomy } \\
\hline MZ-1682 & rev ish $X Y$, enh(2) & $\mathrm{m}$ & $46, X Y / 47, X Y,+2$ & 30 & 7 \\
\hline MZ-2816 & rev ish XY, enh(4) & & $47, X Y,+4$ & 28 & 9 \\
\hline MR-380 & rev ish XX enh(4) & $\mathrm{m}$ & $47, X X,+4$ & 33 & 9 \\
\hline MZ-570 & rev ish $X X$, enh(7) & $f$ & $47, x X+7$ & 33 & 1.trim \\
\hline MR-120 & rev ish $X X$, enh(7) & $\mathrm{m}$ & $47, X X,+7$ (mat) & 33 & 8 \\
\hline MR-137 & rev ish $X Y$, enh(7) & $\mathrm{m}$ & $47 X Y+7$ (pat) & 38 & 11 \\
\hline MR-138 & rev ish $X X$, enh(8) & $\mathrm{m}$ & $47, X X,+8$ & 30 & 11 \\
\hline MZ-4618 & rev ish $X X$, enh(10) & & $47, X X,+10$ & 38 & $9-10$ \\
\hline MZ-2070 & rev ish $X X$, enh(13) & & $47 x x+13$ & 39 & 1. trim \\
\hline MR-67 & rev ish $X Y$, enh(13) & $\mathrm{m}$ & $47, \mathrm{XY},+13$ (mat) & 35 & 10 \\
\hline MZ-4348 & rev ish $X Y$, enh(15) & & $47, X Y+15$ & 37 & 1. trim \\
\hline MR-60 & rev ish $X Y$, enh(15) & & $47, X Y,+15$ & 33 & 7 \\
\hline MZ-1832 & rev ish $X X$, enh(16) & f & $47, x X,+16$ & 31 & 10 \\
\hline MZ-2025 & rev ish $\mathrm{XY}$, enh(16) & $\mathrm{m} / \mathrm{f}$ & $47, X Y+16$ & 31 & 10 \\
\hline MZ-2992 & rev ish $X X$, enh(16) & & $47, x X,+16$ & 29 & 11 \\
\hline MZ-3586 & rev ish $X Y$, enh(16) & $\mathrm{m}$ & $47, X Y+16$ & 34 & 11 \\
\hline MZ-4440 & rev ish $X X$, enh(16) & & $47, X X,+16$ & 30 & 5 \\
\hline MR-106 & rev ish $X Y$, enh(16) & $\mathrm{m}$ & $47, X Y,+16$ (mat) & 28 & 9 \\
\hline MR-159 & rev ish $X Y$, enh(16) & $\mathrm{m}$ & $47, X Y,+16$ (mat) & 30 & 11 \\
\hline MR-258 & rev ish $X Y$, enh(16) & & $47, X Y,+16$ & 23 & 9 \\
\hline MR-291 & rev ish $X X$, enh(16) & $\mathrm{m}$ & $47, \mathrm{XX},+16$ (mat) & 19 & 14 \\
\hline MZ-4616 & rev ish $X X$, enh(18) & & $47, X X,+18$ & 32 & 10 \\
\hline MR-162 & rev ish $X Y$, enh(19) & $\mathrm{m}$ & $46, X Y / 47, X Y+19$ & 21 & 10 \\
\hline MZ-2600 & rev ish $X X$, enh(21) & $\mathrm{m}$ & $47, X X,+21$ & 39 & 11 \\
\hline MR-95 & rev ish $\mathrm{XX}$ enh(21) & $\mathrm{m}$ & $47 x X+21$ & 35 & 12 \\
\hline MZ-3943 & rev ish $X Y$, enh(22) & & $47, X Y+22$ & 35 & 10 \\
\hline MZ-4677 & rev ish $X Y$, enh(22) & $\mathrm{m}$ & $46, X Y / 47, X Y,+22$ & 33 & $8 / 9$ \\
\hline MR-41 & rev ish $X Y$, enh(22) & $\mathrm{m}$ & $47, X Y,+22$ (mat) & 38 & 10 \\
\hline \multicolumn{6}{|c|}{ Monosomy X } \\
\hline MZ-3572 & rev ish $X$ & & $45, x$ & 29 & 12 \\
\hline MR-45 & rev ish $X$ & $\mathrm{~m}$ & $45, X$ (pat) & 38 & 10 \\
\hline
\end{tabular}


Table 1 (Continued)

\begin{tabular}{|c|c|c|c|c|c|}
\hline ID No & $\mathrm{CGH}$ & $\begin{array}{l}\text { Verification } \\
\text { of CGH }\end{array}$ & $\begin{array}{l}\text { Proposed } \\
\text { karyotype } \\
\text { (origin of } \\
\text { aberration) }\end{array}$ & $\begin{array}{l}\text { Maternal } \\
\text { age }\end{array}$ & $\begin{array}{l}\text { Gestational } \\
\text { age }\end{array}$ \\
\hline $\begin{array}{l}\text { Structural anomalies } \\
\text { MZ-1520 }\end{array}$ & rev ish $X X, \operatorname{dim}(5)(p 14 p t e r)$ & & $46, X X, \operatorname{del}(5)(\mathrm{p} 14)$ & 38 & 10 \\
\hline
\end{tabular}

$\mathrm{m}=$ microsatellite analysis, $\mathrm{f}=\mathrm{FISH}$, mat=maternal, pat=paternal. The CGH results are described according to ISCN (1995). Enhanced (enh) and diminished (dim) regions are those where the fluorescence ratio is increased or decreased relative to the euploid (balanced) state.

aberration rates in 60 cases of early spontaneous abortions which had failed to grow in culture.

As an alternative cytogenetic technique CGH circumvents technical problems associated with tissue culturing. In combination with microsatellite analysis and interphase FISH, CGH can identify whole chromosome aneuploidies and all major unbalanced structural chromosome aberrations that are detected by conventional cytogenetic analyses. In our series, CGH shows a lower failure rate (5\%) than conventional cytogenetic analyses. A recent study on spontaneous abortions using CGH in combination with flow cytometry revealed a similar failure rate providing more accurate cytogenetic results by avoiding maternal cell contamination and tissue culture artifacts. ${ }^{21}$

Application of CGH to abortion material in our study detected chromosome abnormalities in $72 \%$ of culture failures. This pointed to an adverse effect of chromosome imbalances on culture growth and thus to a higher chromosome aberration rate in culture failures. Our rate of culture failures was $30.4 \%(\mathrm{MZ})$ and $12.5 \%$ (MR) in first trimester abortions. In the literature, data of overall failure rates range from 10 to $60 \% .^{22,23}$ Our control group comprised 4693 successfully karyotyped first trimester spontaneous abortions showing an aberration rate of $64.8 \%$, exceeding the average value of most previous studies. This result is even more striking when the cases from Marburg with an aberration rate of $71 \%$ are regarded separately. As the MRstudy shows higher success rates in tissue culturing and a low rate of maternal contaminations, as concluded from a sex ratio of 1.0 in the chromosomally normal cases, more 'critical cases', that may or may not grow in culture are included in the control group. The rate of incorrect karyotype assessment by maternal cell contamination has been suggested to be as high as $29-58 \%$ in conventional analysis. ${ }^{24}$ Similarities in distribution of anomalies could, therefore, be due to the fact that both collectives studied overlap and that successfully karyotyped 'critical cases' tend to be chromosomally abnormal.

Autosomal trisomies were most common in both groups, yet of a higher abnormality rate $(68.3 \%)$ in chromosomally abnormal CGH cases compared to a rate of $53.9 \%$ in our
non-CGH cases and approximately $55 \%$ in pooled literature data. Complete trisomy for each chromosome, including chromosome 1, has meanwhile been identified in early spontaneous abortions with trisomies 16, 21 and 22 being the most frequent. ${ }^{25,26}$ The distribution of individual trisomies in our CGH and non-CGH cases, however, are comparable with the exception of trisomy 7 . The high incidence of trisomy $7(10.2 \%)$ in our CGH series is most striking. Together with trisomy 22 , trisomy 7 is the second most common trisomy compared to a $3.2 \%$ rate of our nonCGH control group and a $3.4 \%$ rate of other studies. ${ }^{26}$ However, intergroup differences in the frequency of trisomy 7 were of borderline significance $(P=0.08)$. Recent molecular studies of autosomal trisomies 16, 18, and 21 have shown that non-disjunction originated predominantly from maternal meiosis I and that factors such as abnormal recombinations play an important role in its genesis. ${ }^{27-29}$ Zaragoza et $a l^{30}$ confirmed this for trisomies 15 and 22 but revealed a different etiology for chromosome 7 . In more than half of the cases trisomy 7 originated from mitotic non-disjunction. Furthermore, chromosome 7 has been shown to be imprinted. Pre- and postnatal growth failure associated with maternal uniparental disomy 7 has been reported indicating the presence of several imprinted growth genes or growth receptors such as peg $1 /$ mest, GRB10. ${ }^{31}$ However, trisomy 7 is a relatively common pseudomosaic finding in prenatal cytogenetic analysis suggesting that at least in the mosaic condition proliferative disadvantage may be compensated by euploid cells. ${ }^{32,33}$

The frequency of triploidy in the growth failure CGH series $(17.1 \%)$ was slightly above that of our control group (15.6\%). Warburton et $a l^{34}$ distinguished between triploid abortions due to dispermy and digyny, and calculated relations of $1 \mathrm{XXX}: 2 \mathrm{XXY}: 1 \mathrm{XYY}$ for the former and 1XXX: 1XXY for the latter condition. In practice XYY triploids have rarely been observed, accounting for about $3 \%$ of all triploids and were associated with early embryonic demise. ${ }^{34,35}$ In our own material we found a relation of $1.5 X X X: 1 \mathrm{XXY}: 1 \mathrm{XYY}(n=7)$ in the CGH series and of 1XXX: 1.5XXY:0.08XYY $(n=459)$ in the cytogenetically analysed abortion material. The observed differences in 
a.

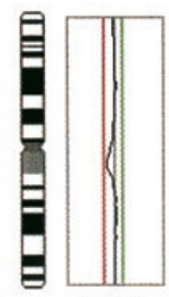

1(14)

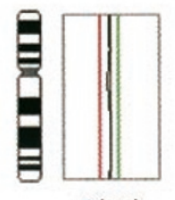

$7(20)$

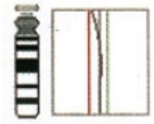

15(16)

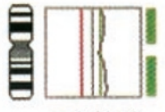

$16(21)$
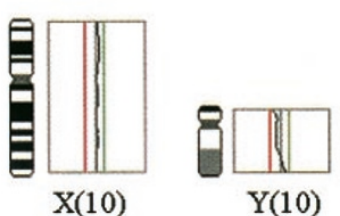

b.

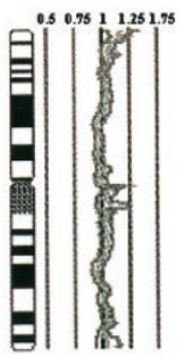

1(24)
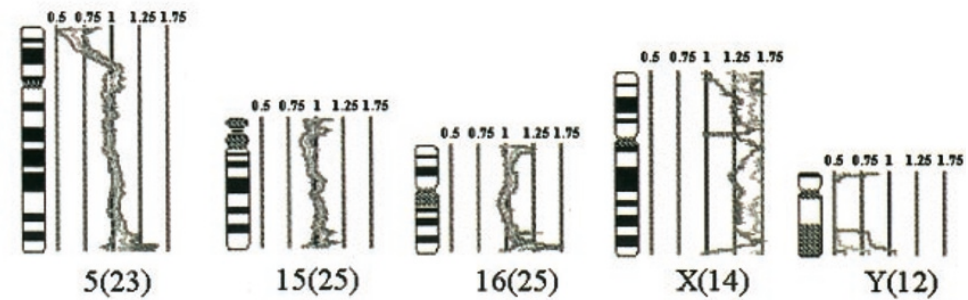

$\mathrm{X}(14)$

Figure 1 (a) missed abortion in 11th g.w. (MR-159); partial CGH profile showing male karyotype with gain of chromosome 16. Chromosomes 1, 7, 15 are added for comparison. (b) missed abortion in 10th g.w. (MZ-1520); partial CGH profile showing female karyotype with loss of chromosome 5 p14 $\rightarrow$ pter (chromosome 1, 15, 16 shown for normal profiles).

Table 2 Characteristics of spontaneous abortions which failed to grow in culture

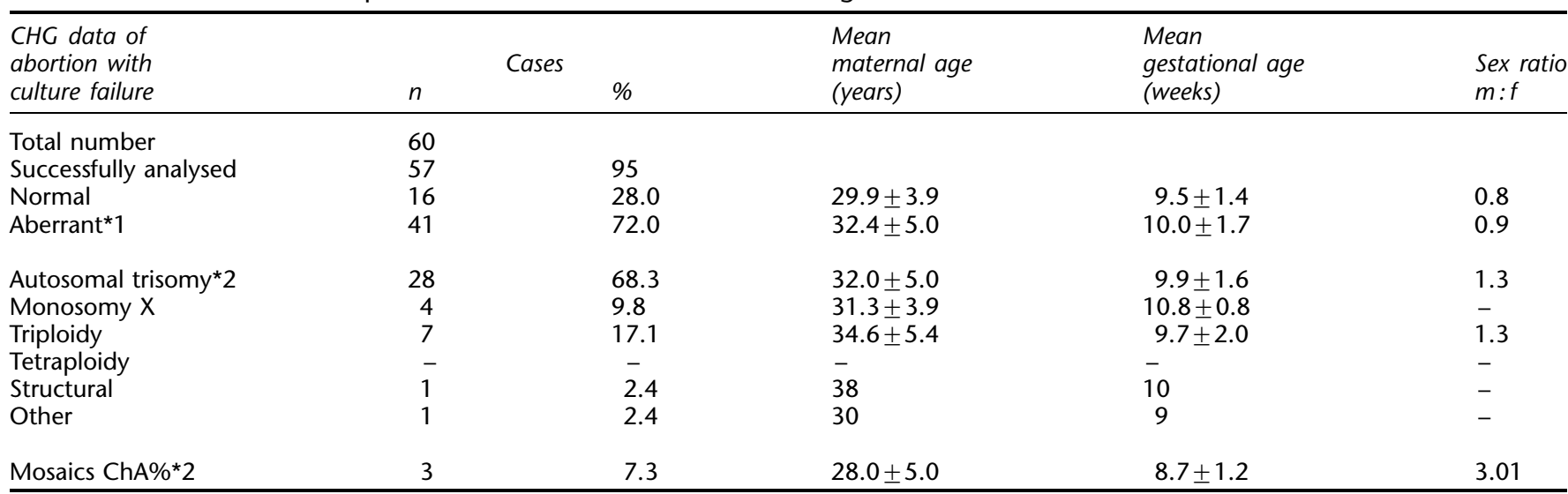

*1 including one complete mole; ${ }^{*} 2$ including three mosaic karyotypes. Mosaic karyotypes have been included in the major aberration group. $\mathrm{ChA}=$ Chromosomal abnormality.

numbers of XYY-triploids was statistically significant $(P=0.02)$. We, therefore, suggest in accordance with the early observations of Boué $e t \mathrm{al}^{17}$ that the small number of $69, \mathrm{XYY}$ constitution in the reported surveys can be explained by the fact that this karyotype leads to very early developmental arrest and to insufficient growth in tissue culture. The excess of females observed in spontaneous abortions may be due to karyotyping of maternal cells giving rise to an underestimation of the true incidence of aneuploidy in spontaneous abortions. ${ }^{24,36,37}$ Interestingly, $\mathrm{CGH}$ evidenced an altered male: female sex ratio of $1: 1.3$
(0.77). In $\mathrm{CGH}$, it is methodically unlikely for this altered sex ratio to be due to maternal cell contamination. We, therefore, postulate that the predominance of the females in culture failures represents a biological phenomenon.

Despite our promising results, however, CGH does have some limitations in the evaluation of abortion specimens. Ploidy changes found in approximately 30\% of abortion specimens are not detected as shown for all $69, \mathrm{XXX}$ cases in our series. One further troubling aspect of $\mathrm{CGH}$ for the detection of copy number anomalies is that this assay is insensitive in regions of high variability which is relatively 
Table 3 Control group comprising 4693 successfully karyotyped first trimester spontaneous abortions (pooled data from Mainz and Marburg)

\begin{tabular}{|c|c|c|c|c|c|}
\hline $\begin{array}{l}\text { First trimester } \\
\text { abortion specimens }\end{array}$ & $n$ & Cases & $\begin{array}{l}\text { Mean } \\
\text { maternal age } \\
\text { (years) }\end{array}$ & $\begin{array}{l}\text { Mean } \\
\text { gestational age } \\
\text { (weeks) }\end{array}$ & $\begin{array}{l}\text { Sex ratio } \\
m: f\end{array}$ \\
\hline Total number & $6631(43)$ & - & & & \\
\hline Normal & $1653(110)$ & $35.2(29.0)$ & $30.3 \pm 4.5$ & $9.8 \pm 1.6$ & $0.6(1.0)$ \\
\hline Aberrant $^{a}$ & 3040 (269) & $64.8(71.0)$ & $31.4 \pm 4.8$ & $9.9 \pm 1.4$ & $0.9^{\mathrm{b}}(0.9)$ \\
\hline Triploidy & $459(25)$ & $15.6(9.3)$ & $29.6 \pm 3.9$ & $9.7 \pm 1.5$ & $1.6(1.3)$ \\
\hline Tetraploidy & $344(13)$ & $11.3(4.8)$ & $29.9 \pm 4.3$ & $9.6 \pm 1.4$ & $0.7(1.2)$ \\
\hline Structural & $275(31)$ & $9.0(11.5)$ & $30.8 \pm 4.6$ & $9.5 \pm 1.4$ & $0.7^{c}(1.8)$ \\
\hline Mosaic \%ChA & $457(26)$ & $15.0(11.6)$ & $30.7 \pm 4.5$ & $9.6 \pm 1.4$ & $0.6^{c}(1.0)$ \\
\hline
\end{tabular}

${ }^{a}$ Complete hydatiform moles with $46, X X$-karyotype included. ${ }^{b}$ Complete hydatiform moles with $46, X X$-karyotype and cases with monosomy $X$ excluded. 'Cases with monosomy $X$ excluded. Number in brackets mark separate data from Marburg showing higher culture success and chromosomal aberration rates and lower maternal contamination indicated by a sex ratio of 1.0. Mosaic karyotypes have been included in the major aberration group since differing numbers of cells analysed made a more accurate estimation of mosaicism difficult.

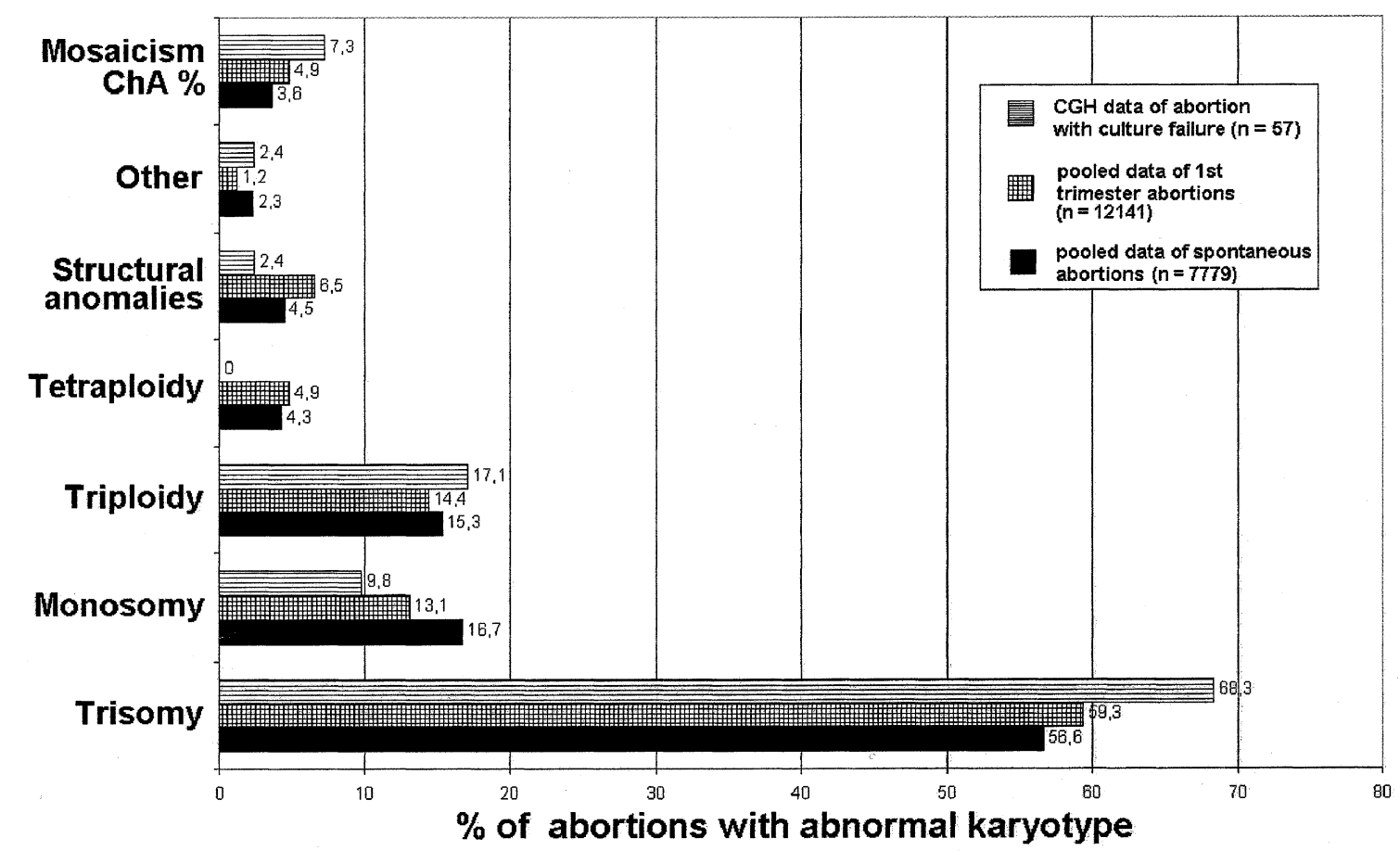

Figure 2 Distribution of chromosome anomalies: comparison of CGH data on abortions after culture failure with pooled data of cytogenetically analysed first trimester spontaneous abortions ${ }^{19,20,23,42-45}$, this study and with pooled data of spontaneous abortions including abortions beyond 14 g.w. ${ }^{18,22,34,36,46-56}$

important for the chromosome regions $1 \mathrm{p} 32 \rightarrow$ pter, $16 \mathrm{p}, 19$ and $22 .{ }^{15}$ Trisomy 16 and 22 , however, are frequently found in abortions accounting for about $40-50 \%$ of the trisomic specimens. ${ }^{26}$ Therefore, additional methods such as microsatellite analysis or interphase FISH are required, and as shown in our series can bridge this gap. Theoretically, detection of deletions by $\mathrm{CGH}$ is in the range of $2-5 \mathrm{Mb}{ }^{38}$ To date, however, only deletions in the $10-15 \mathrm{Mb}$ range have been successfully demonstrated by CGH. ${ }^{5,7,39}$ The $5 p$ deletion comprising the region 5 pter $\rightarrow$ p14 identified by 
CGH in our series was well above the lower detection limit (Figure 1).

At the time CGH is predominantly restricted to research applications, but recently, this method was successfully applied in clinical cytogenetics to detect and characterise whole or segmental aneuploidies on different kinds of tissues such as blood, chorionic villi, and amniocytes. ${ }^{6-8,40,41}$ Since CGH requires such highly specialised techniques as DNA extraction, labelling using nick-translations kits and hybridisation, setting up CGH for clinical use demands time and effort. An average cytogenetic laboratory needs about 6 months to establish the technique. ${ }^{15}$ This can be confirmed by our laboratory. The main disadvantage of CGH for a cytogenetic service laboratory, however, may be the cost of the required image analysis system. Once established, we estimate, that the cost of $\mathrm{CGH}$ is within a reasonable range compared with other cytogenetical methods using in situ hybridisation.

Nevertheless, CGH extends the diagnostic spectrum considerably facilitating diagnosis of chromosome aberrations in hitherto unresolved abortion cases. On the basis of the present data it seems reasonable to assume that the genetic contribution to pregnancy losses is still underestimated. Pooled data of 22 studies using conventional cytogenetic methods result in an average frequency of chromosome abnormalities of 52\% (Figure 2). Restricting estimations to first trimester abortion cases only, the frequency rate is higher at $57 \%$. Estimations thus far, however, do not take into account cases of culture failures amounting to $10-60 \%$ of conventional analyses. If we transfer our results of a $72 \%$ chromosome aberration rate among cases with culture failure onto the total number of culture failure in our cytogenetic study we reach an aberration rate of $67 \%$ among first trimester spontaneous abortions. Therefore, in view of our investigation into this hitherto unexplored segment the total percentage of aberrant early foetal losses has to be estimated well beyond $65 \%$. By elimination of maternal cell contamination the aberration rate would be further enhanced. This rate of chromosomal aneuploidy in early spontaneous abortions is higher than, in general, currently accepted. Since the outcome of subsequent pregnancies varies on the presence/absence of chromosome disturbances in a previous abortion correction towards a higher aberration rate gives a more positive outlook in counselling patients with a past history of early foetal losses.

\section{Acknowledgements}

The cooperation of numerous obstetricians is gratefully acknowledged. Particularly, we wish to thank Dr M Scharsich, gynäkologische und geburtshilfliche Abteilung des Krankenhauses Wehrda, Marburg. We are gratefully indebted to Dr Jutta Köhler for proof-reading of the manuscript and for linguistic suggestions, and to Evelyn Winkler (MR) and Susan Mankovi (MZ) for excellent technical assistance. This work was supported in parts by PE Kempkes Stiftung Marburg, by the Universitätsinterne Forschungsförderungs programme der Johannes
Gutenberg Universität Mainz B5 - Neue Technologien, and by the DFG (FR1302/1-2).

\section{References}

1 Kallioniemi A, Kallioniemi OP, Sudar D et al: Comparative genomic hybridization for molecular cytogenetic analysis of solid tumors. Science 1992; 258: 818-821.

2 Nacheva E, Grace CD, Bittner M, Ledbetter DH, Jenkins RB, Green AR: Comparative genomic hybridization: a comparison with molecular and cytogenetic analysis. Cancer Genet Cytogenet 1998; 100: 93-105.

3 Lapierre JM, Chacheux V, Da Silva F et al: Comparative genomic hybridization: technical development and cytogenetic aspects for routine use in clinical laboratories. Ann Genet 1998; 41: 56 62.

4 Daniely M, Barkai G, Goldman B, Aviram-Goldring A: Detection of numerical chromosome aberrations by comparative genomic hybridization. Pren Diagn 1999; 19: 100-104.

5 Daniely M, Barkai G, Goldman B, Aviram-Goldring A: Structural unbalanced chromosome rearrangements resolved by comparative genomic hybridization. Cytogenet Cell Genet 1999; 86: 51 55 .

6 Erdel M, Duba HC, Verdorfer I et al: Comparative genomic hybridization reveals a partial de novo trisomy 6 q23 $\rightarrow$ qter in an infant with congenital malformations: delineation of the phenotype. Hum Genet 1997; 99: 596-601.

7 Levy B, Gershin IF, Desnick RJ et al: Characterization of a de novo unbalanced chromosome rearrangement by comparative genomic hybridization and fluorescence in situ hybridization. Cytogenet Cell Genet 1997; 76: 68-71.

8 Benzacken B, Lapierre JM, Siffroi JP, Chalvon A, Tachdjian G: Identification and characterization of a de novo partial trisomy $10 \mathrm{p}$ by comparative genomic hybridization (CGH). Clin Genet 1998; 54: $334-340$.

9 Aviram-Goldring A, Fritz B, Bartsch C et al: Molecular cytogenetic studies in three patients with partial trisomy $2 \mathrm{p}$, including CGH from paraffin-embedded tissue. Am J Med Genet 2000; 91: 74-82.

10 Fritz B, Greber-Platzer S, Streubel B et al: Familial cryptic translocation with del q34 $\rightarrow$ qter and dup12pter $\rightarrow$ p13 in sibs with tracheal stenosis-Clinical, classical and molecular cytogenetic studies and CGH analyses from archival placental tissues evidencing tertiary trisomy 4 in one abortion specimen. Am J Med Genet 2000; 97: 271-280.

11 Voullaire L, Slater H, Williamson R, Wilton L: Chromosome analysis of blastomeres from human embryos by using comparative genomic hybridization. Hum Genet 2000; 106: $210-217$.

12 Miller SA, Dykes DD, Polesky HF: A simple salting out procedure for extracting DNA from human nucleated cells. Nucleic Acid Res 1988; 16: 1215.

13 Kallioniemi OP, Kallioniemi A, Piper J et al: Optimizing comparative genomic hybridization for analysis of DNA sequence copy number changes in solid tumors. Genes Chromosomes Cancer 1994; 10: $231-243$.

14 Du Manoir S, Schröck E, Bentz M et al: Quantitative analysis of comparative genomic hybridization. Cytometry 1995; 19: 27 41.

15 Bryndorf T, Kirchhoff M, Rose $\mathrm{H}$ et al: Comparative genomic hybridization in clinical cytogenetics. Am J Hum Genet 1995; 57: $1211-1220$.

16 Don RH, Cox PT, Wainwright BJ, Baker K, Mattrick JS: 'Touchdown' PCR to circumvent spurious priming during gene amplification. Nucleic Acids Res 1991; 21: 783.

17 Boué A, Boué J, Gropp A: Cytogenetics of pregnancy wastage. In: Harris H, Hirschhorn K (eds): Advances in human genetics. Vol 14 New York, Plenum Press, 1985, pp. 1-57. 
18 Be C, Velásquez P, Youlton R: Aborto espontaneo: estudio citogenetico en 609 casos. Rev Med Chile 1997; 125: 317 - 322

19 Strom CM, Ginsberg N, Applebaum M et al: Analyses of 95 firsttrimester spontaneous abortions by chorionic villus sampling and karyotype. J Ass Reprod Genet 1992; 9: 458-461.

20 Guerneri S, Bettio D, Simoni G, Brambati B, Lanzani A, Fraccaro $\mathrm{M}$ : Prevalence and distribution of chromosome abnormalities in a sample of first trimester internal abortions. Human Reprod 1987; $2: 735-739$.

21 Lomax BL, Tang S, Separovic E et al: Comparative genomic hybridization (CGH) in combination with flow cytometry improves results of cytogenetic analysis of spontaneous abortions. Am J Hum Genet 2000; 66: 1516-1521.

22 Dejmek J, Voitassak J, Malova J: Cytogenetic analysis of 1508 spontaneous abortions originating from south Slovakia. Eur J Obstet Gynecol Reprod Biol 1992; 46: 129-136.

23 Gardó S, Bajnóczky K: Cytogenetic analysis of spontaneous abortion with direct analysis of chorionic villi. Eur J Obstet Gynaecol Reprod Biol 1992; 47: 117-120.

24 Bell KA, van Deerlin PG, Haddad BR, Feinberg RF: Cytogenetic diagnosis of 'normal $46, \mathrm{XX}^{\prime}$ ' karyotypes in spontaneous abortions frequently may be misleading. Fertility and Sterility 1999; 71: $334-341$.

25 Sanford HJ, Shires P, Matile G: Trisomy 1 in a clinically recognized pregnancy. Am J Med Genet 1997; 68: 98.

26 Hassold T, Abruzzo M, Adkins $\mathrm{K}$ et al: Human aneuploidy: Incidence, Origin and Etiology. Environ Molec Mutagen 1996; 28 $167-175$.

27 Hassold TJ, Merrill M, Adkins K, Freeman S, Sherman S: Recombination and maternal age dependent non disjunction: molecular studies of trisomy 16. Am J Hum Genet 1995; 57: 867 874

28 Fisher JM, Harvey JF, Morton NE, Jacobs PA: Trisomy 18: studies of the parent and cell division of origin and the effect of aberrant recombination on nondisjunction. Am J Hum Genet 1995; 56: 669-675.

29 Lamb NE, Freeman SB, Savage-Austin A et al: Susceptible chiasmate configuration of chromosome 21 predispose to non-disjunction in both maternal meiosis I and meiosis II. Nat Genet 1996; 14: 400-405.

30 Zaragoza MV, Millie E, Redline RW, Hassold TJ: Studies of non disjunction in trisomies $2,7,15$, and 22: does the parental origin of trisomy influence placental morphology? J Med Genet 1998; 35: 924-931.

31 Kotzot D, Balmer D, Baumer A et al: Maternal uniparental disomy 7 -review and further delineation of the phenotype. Eur J Pediatr 2000; 159: 247-256.

32 Hsu LYF, Kaffe S, Jenkins EC et al: Proposed guidelines for diagnosis of chromosome mosaicism in amniocytes based on data derived from chromosome mosaicism and peudomosaicism studies. Prenat Diagn 1992; 12: 555- 573.

33 Kalousek D, Langlois S, Robinson WP: Trisomy 7 CVS Mosaicism: Pregnancy outcome, placental and DNA analysis in 14 cases. Am J Med Genet 1996; 65: 348-352.

34 Warburton D, Stein Z, Kline J, Susser M: Chromosome abnormalities in spontaneous abortion: Data from the New York City study. In: Porter IH, Hook EB (eds): Human embryonic and fetal death. New York, Academic Press 1980, pp. 216- 287.

35 Zaragoza MV, Surti U, Redline RW, Millie E, Chakravarti A, Hassold TJ: Parental origin and phenotype in spontaneous abortions: predominance of diandry and association with the partial hydatidiform mole. Am J Hum Genet 2000; 66: 1807 1820.
36 Eiben B, Bartels I, Bähr-Porsch S et al: Cytogenetic analysis of 750 spontaneous abortions with the direct method of chorionic villi and its implications for studying genetic causes of pregnancy wastage. Am J Hum Genet 1990; 47: 656-663.

37 Bartels I, Hansmann I, Eiben B: Excess of females in chromosomally normal spontaneous abortuses. Am J Med Genet 1990; 35: $297-298$.

38 Piper J, Rutovitz D, Sudar D et al: Computer image analysis of comparative genomic hybridization. Cytometry 1995; 19: 1026.

39 Bentz M, Plesch A, Stilgenbauer S, Dohner H, Lichter P: Minimal size of deletions detected by comparative genomic hybridization. Genes Chromosomes Cancer 1998; 21: 172-175.

40 Lapierre JM, Cacheux V, Luton D et al: Analysis of uncultured amniocytes by comparative hybridization: a prospective prenatal study. Prenat Diagn 2000; 20: $123-131$.

41 Ozcan T, Burki N, Parkash V et al: Cytogenetical diagnosis in paraffin-embedded fetoplacental tissue using comparative genomic hybridization. Prenat Diagn 2000; 20: 41-44.

42 Boué J, Boué A, Lazar P: Retrospective and prospective epidemiological studies of 1500 karyotyped spontaneous abortions. Teratology 1975; 12: $11-26$.

43 Neuber $M$, Rehder $H$, Zuther C, Lettau R, Schwinger E: Polyploidies in abortion material decrease with maternal age. Hum Genet 1993; 91: $563-566$.

44 Kalousek DK, Pantzar T, Tsai M, Paradice B: Early spontaneous abortion: morphologic and karyotypic findings in 3912 cases. Birth Defects Orig Artic Ser 1993; 29: 53-61.

45 Ford JH, Wilkin HZ, Thomas P, McCarthy C: A 13 Year cytogenetic study of spontaneous abortion: Clinical applications of testing. Aust NZ J Obstet Gynaecol 1996; 36: 314-318.

46 Creasy MR, Crolla JA, Ablerman ED: A cytogenetic study of human spontaneous abortions using banding techniques. Hum Genet 1976; 31: 177-196.

47 Lauritsen JG: Aetiology of spontaneous abortion. Acta Obstet Gynecol Scand 1976; Suppl 52: 2-29.

48 Takahara H, Ohama K, Fujiwara A: Cytogenetic study in early spontaneous abortion. Hiroshima J Med Sci 1977; 26: 26-31.

49 Geisler M, Kleinebrecht J: Cytogenetic and histologic analyses of spontaneous abortions. Hum Genet 1978; 45: 239-251.

50 Kajii T, Ferrier A, Niikawa N, Takahara H, Ohama K, Avirachan S: Anatomic and chromosomal anomalies in 639 spontaneous abortuses. Hum Genet 1980; 55: 87-98.

51 Andrews P, Dunlop W, Roberts DF: Cytogenetic studies in spontaneous abortuses. Hum Genet 1984; 66: 77-84.

52 Hassold TJ: Chromosome abnormalities in human reproductive wastage. Trends Genet 1986; 2: $105-109$.

53 Ohno M, Maeda T, Matsunobu A: A cytogenetic study of spontaneous abortions with direct analysis of chorionic villi. Obstet Gynecol 1991; 77: 394-398.

54 Cowchock S, Gibas Z, Jackson LG: Chromosome errors as a cause of spontaneous abortion: the relative importance of maternal age and obstetric history. Fertility and Sterility 1993; 59: $1011-$ 1014.

55 Brajencovi-Milic B, Petrovi O, Krasevic M, Ristic S, Kapovic M: Chromosomal anomalies in abnormal human pregnancies. Fetal Diagn Ther 1998; 13: 187-191.

56 Sánchez JM, Franzi L, Collia F, de Díaz SL, Panal M, Dubner M: Cytogenetic study of spontaneous abortions by transabdominal villus sampling and direct analysis of villi. Prenat Diagn 1999; 19: $601-603$ 